\title{
Thickened tailings water balance - dealing with excess water
}

\author{
J. Moreno SRK Consulting Australia, Australia \\ J. Martin SRK Consulting Australia, Australia \\ D. Luppnow SRK Consulting Australia, Australia
}

\section{Abstract}

Thickened tailings facilities are often designed to contain limited amounts of supernatant water, or even planned to rely on evaporative capacity of the receiving environment. While this is feasible depending on particular site conditions, it may be difficult to estimate water storage volumes. The latter is necessary to size a cost-effective pond for managing free water released from the tailings mass and it is one of the components when deciding whether to evaporate it or to return it into the process.

This paper presents some of the design issues found by the authors when dealing with excess water for thickened tailings facilities. The approach is to discuss water balance timescales, incorporating true-surface flux boundary infiltration models, variability of the underflow density and probabilistic inputs. The objective is to identify the most influencing factors when designing water management elements for thickened tailings facilities.

\section{Introduction}

One of the main advantages of thickened tailings disposal, especially in arid environments, is the limited amount of water reporting to the downstream boundary of the facility. In correspondence with the latter, downstream embankments, or containment barriers, are optimised to retain mainly tailings, with water being evaporated.

The process of releasing off the entrained water within the tailings pores is usually very difficult to describe and needs complex models dealing with processes such as consolidation, desiccation and unsaturated water transport techniques, in conjunction with extensive experimental data from laboratory and from site trials. Accuracy of the desiccation and unsaturated transport models would depend on the quality of the input data. A rigorous approach would include application of a true-surface flux boundary at the top of the tailings, where climatic conditions are replicated from known databases and evaporation is estimated from first principles. This is discussed along with its use in water balance estimations.

Unexpected free excess water mostly occurs when thickening targets are not met or when further thickening occurs after deposition. A way of exploring these effects is to introduce probabilistic analysis of water balances where appropriate ranges for the key inputs are defined. These are described in the article along with a discussion on improving design reliability when dealing with excess water in a thickened tailings storage facility (TSF).

\section{Water available with disposed tailings}

The amount of water that comes mixed in the slurry exiting the thickener is usually reported as a fraction of the total weight of the slurry, we refer to this ratio as 'solids content' $(\mathrm{Cw})$ where $\mathrm{Cw}=$ dry weight of solids/total weight of slurry. For a given slurry, the amount of water is dependent on the specific gravity (SG) of the tailings from one side and on the tailings tonnages produced from the other. Variation in SG is usually not greater than $2-5 \%$, the influence of this factor is commonly neglected, and working with an average SG provides sufficient accuracy for water balance calculations. 
The performance of modern thickeners is quite reliable, provided that flocculant dosages and ore feed are consistent; close monitoring of the slurry in the thickener allows for quick adjustments of the operation to enhance density of the underflow if necessary. There are, however, a number of factors that affect the thickening underflow density of tailings, such as variability of the ore mineralogy, milling size and $\mathrm{pH}$ of the slurry among the most frequent, however, discussion of these are outside the scope of this paper.

From recent experience, it seems that one of the most influential factors in estimating free excess water is the variability of $\mathrm{CW}$ due to underperformance of the thickeners. An example of this free excess water reporting to a TSF is presented in Figure 1 . This chart describes the excess water reporting to the TSF that occurs when the $\mathrm{Cw}$ target is not met. Free excess water is reported for selected lower $\mathrm{Cw}$ values in correspondence with throughput.

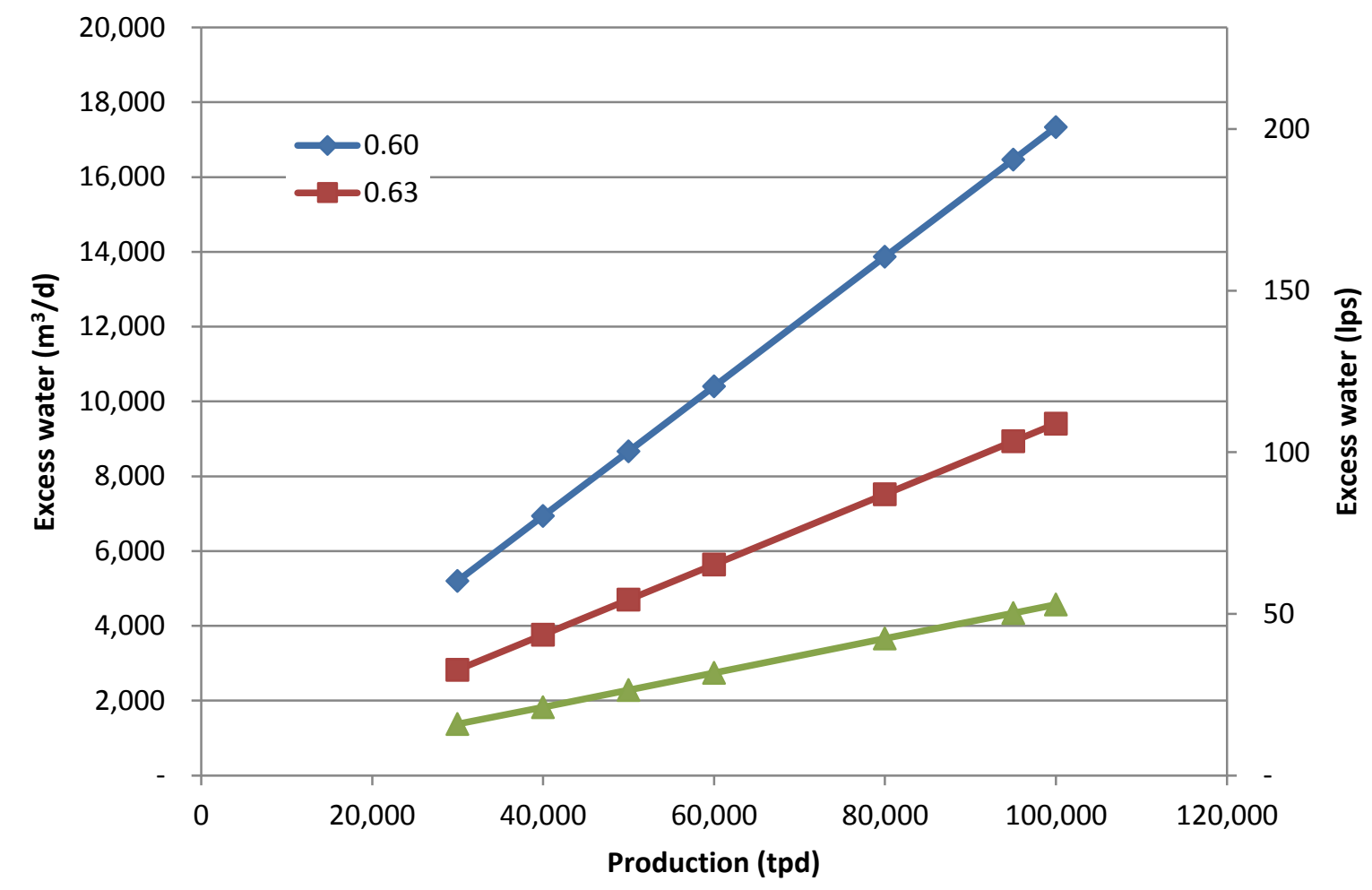

Figure 1 Excess water for a base case of $s \%=67 \%$

The fate of the excess water due to under-thickening is hard to track, however, it mostly falls into three categories:

- Runs off the tailings surface once slurry consolidates and desiccates.

- Evaporates out directly from the pores.

- Infiltrates into tailings lift immediately below.

The last two categories can be modelled with reasonable accuracy; however, the first one is complex and difficult to interpret. Finite strain consolidation theory coupled with desiccation models should be used (Abu-Hejleh and Znidarcic, 1995), since consolidation properties of slurry are not well described by conventional soil mechanics. Therefore, it could be simplified that the excess water falling into the first category is the difference between the last two and the total excess water.

\section{Infiltration modelling}

State-of-the-art for infiltration modelling incorporates unsaturated flow simulation with a true surface flux boundary where climatic conditions are input from first principles. In high evaporative environments thickened tailings would desaturate in just a few days, therefore the need for unsaturated techniques to 
obtain an accurate interpretation of the water balance. In wet environments, on the other hand, it could be possible that thickened tailings would remain saturated, thus self-weight consolidation would govern the release of excess water from the slurry.

In both cases, the changes in volume while the slurry releases pore water to achieve its field density are difficult to model since most of the codes do not incorporate changes in porosity in transient calculations. Modelling initial conditions therefore, can be a source of inaccuracies when selecting initial pore pressure conditions and should be carefully evaluated. A formal approach would include coupling consecutive models as consolidation, desiccation and desaturation (Oliveira-Filho and van Zyl, 2006a, 2006b), each with independent inputs and procedures, however, these are expensive and time consuming and its practicality should be evaluated in light of the quality of the data available.

Figure 2 shows a plot with the evolution of moisture content of various tailings samples after deposition, these tailings were exposed to high evaporation conditions. In order to avoid misrepresentation of moisture content of the tailings profile, such as quick crusting of the surface, samples were taken from at least $0.3 \mathrm{~m}$ deep in all cases. There is a zone indicated in Figure 2 as 'saturated fringe' which corresponds to when tailings start becoming unsaturated. In other words, changes in void ratio profiles due to evaporation (and consequent water release) are likely to occur while void ratios are still above that at the shrinkage limit (Oliveira-Filho and van Zyl, 2006a, 2006b). To obtain a correct interpretation of the modelling results, analysis of this range should be included in the scenarios investigated.

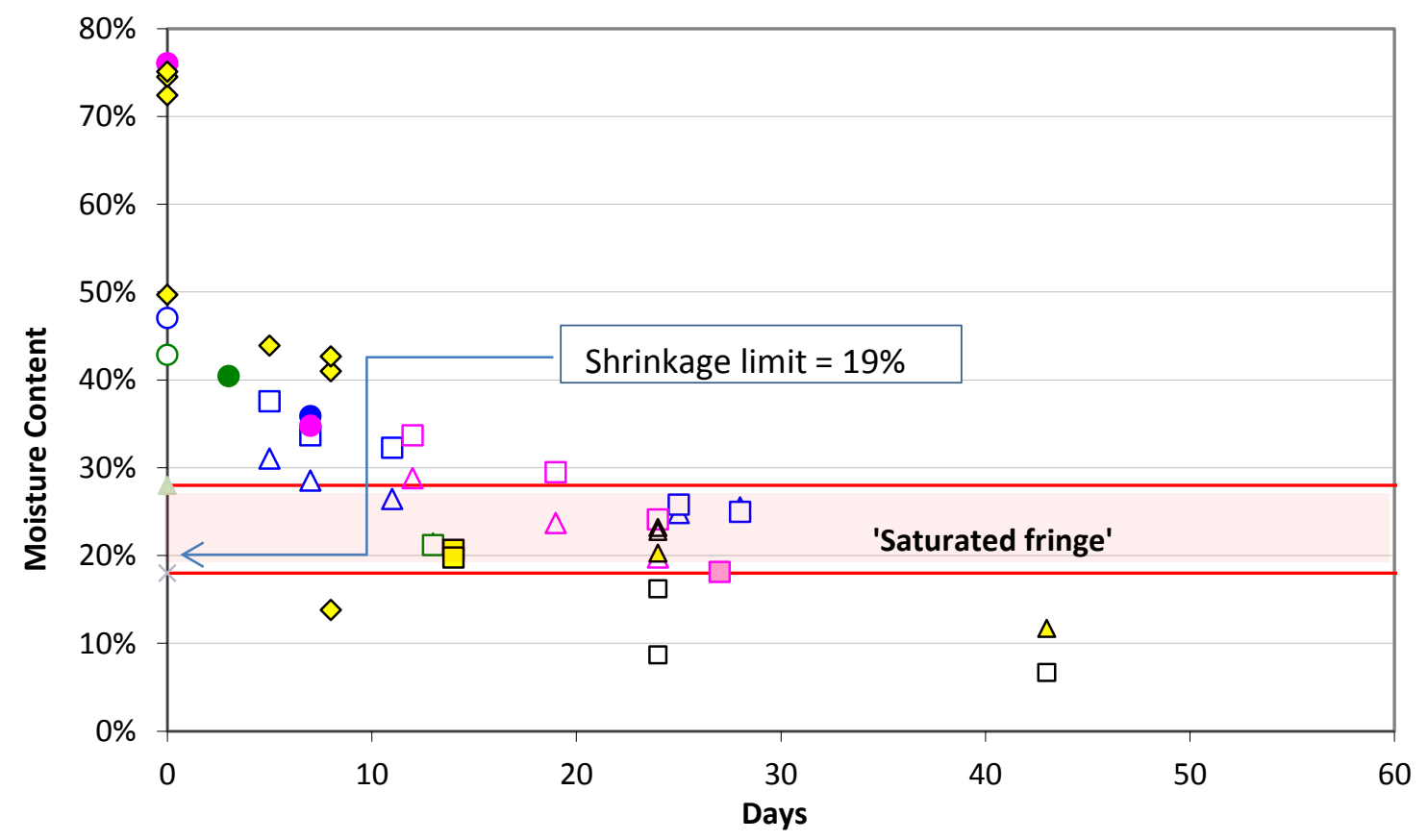

Figure 2 Evolution of moisture content for various thickened tailings samples

Most of the saturated zone water balance components are relatively well understood and can be estimated or measured with relative ease and with a high degree of confidence. However, the same cannot be said for the surface flux boundary components above the unsaturated zone; the measurement of these fluxes is difficult and needs special attention (Rykaart et al., 2001). Unsaturated permeability is a non-linear function of the soil suction which in turn is related to water content. Soil Water Characteristic Curves (SWCC) describe the correspondence between moisture content and suction in the soils pores and from there permeability can be correlated to moisture content (Fredlund et al., 1994). SWCC may be obtained from samples remoulded to the expected field density of the tailings.

Since deposition of tailings is normally rotated around the disposal area to allow drying out and consolidation of the slurry, modelling of the infiltration within the tailings mass is better performed using sequential lifts, simulating cyclic deposition. This is achieved by conducting transient runs one after the 
other, setting a similar timing as the expected deposition cycle. The final calculated pore pressures for each lift is used as initial conditions for the next step and the process is repeated to complete the expected tailings thickness. Figure 3 shows a model of six consecutive tailings lifts, each representing a one month cycle.

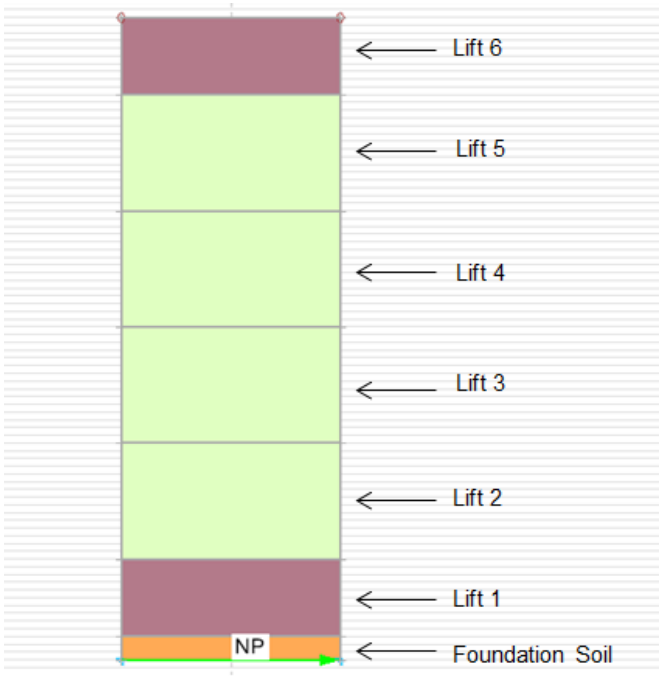

Figure 3 Modelling interaction of consecutive tailings lifts. NB: 180 days of tailings deposition, each upper lift surface was subject to a climate boundary for one month respectively

The final set of results would represent the total amount of water stored in the tailings mass and total water lost to infiltration through the base lift. Figure 4 shows the change in degree of saturation of Lift 1 for the model shown in Figure 3.

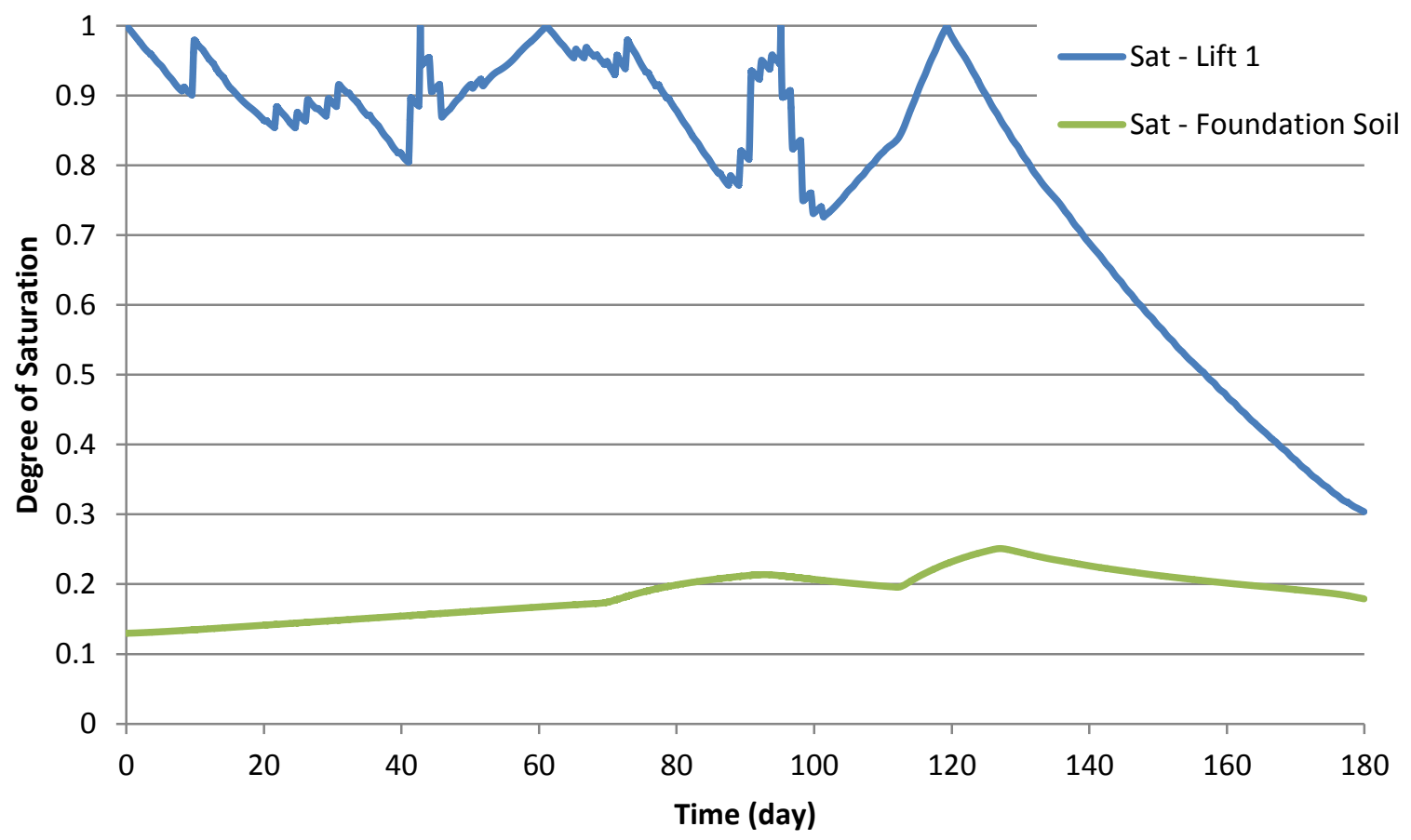

Figure 4 Saturation of Lift 1 due to active tailings deposition through 180 days

Some software such as SVFlux ${ }^{\circledR}$, perform an independent water balance of each lift run calculating the water infiltrated into the lift below and the water evaporated through the upper boundary. However, results from this balance are only useful for comparative purposes and should not be used for tailings water balance calculations since a real representation of the exposed tailings beach areas is not considered in 
these models. Potential evaporation (PE) and actual evaporation (AE) are also obtained from these models and provide a good estimation of the evaporation as input for water balance models. An example of these results can be seen in Figure 5 .

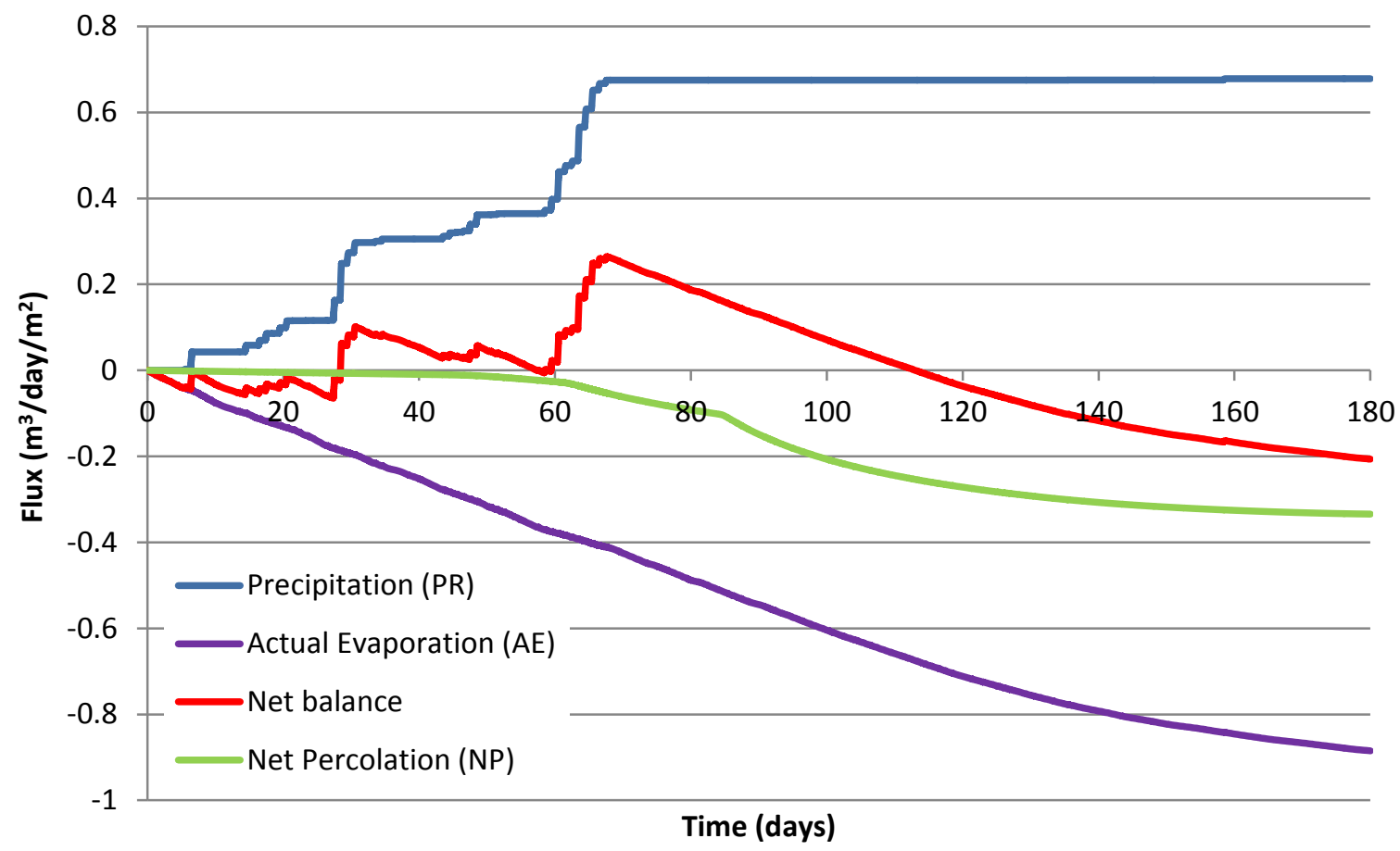

Figure 5 Net balance of consecutive lift deposition

\section{$4 \quad$ Water balance modelling}

Water balance modelling is usually conducted with the assistance of specialised software such as GoldSim ${ }^{\circledR}$ or customised spreadsheets usually built in Microsoft Excel ${ }^{\circledR}$. Decisions on the appropriate tool and complexity of the model depends on the level of accuracy required and quality of the available information (i.e. precipitation records).

A detailed water balance model would require a daily time step setup, while for a pre-feasibility level project a monthly analysis could be sufficient. However, the time step should be defined by assessing the consistency of the data available and, where lower quality information and/or gaps in the data are found, sensitivity of these inputs should be performed introducing probabilistic techniques.

As discussed before, variability of the solids content is an important factor when determining excess water from thickened tailings, this is even critical during start-up of the plant when large variabilities in thickening rates could be experienced and may be sustained for few months before the plant reaches stability. Since this factor is unknown at design stage, probabilistic function of solids content of the slurry should be implemented in the model. Solid content series could be simulated as a random function using the target thickening rate and a specified standard deviation. Standard deviation could be modelled to reflect improvement of the thickener performance with time.

The amount of water trapped in the tailings pores is usually pondered from limited testing and is considered constant throughout the operation. If a detailed infiltration model including unsaturated water transport is available, the pore water volumes calculated from this model can be used to obtain a more realistic estimation of this input, see Figure 4.

Another valuable output from the infiltration model is the calculated PE and AE. From the model, the ratio $\mathrm{AE} / \mathrm{PE}$ is related to a given change in moisture content (or solids content), allowing for various 
discriminating evaporative conditions according to aging of the deposited areas. This way, fresh tailings areas would be subject to a larger AE than older (and drier) tailings areas, see Figure 5.

When using specialised software, complex inputs can be incorporated to water models to improve reliability of the outputs and aid in the interpretation of the results. Probabilistic functions of selected parameters, such as precipitation and solids content, could be built into the model and using Monte Carlo simulation techniques several realisations can be run to explore critical and average conditions. The number of realisations would depend on the reliability of the input parameters. An example of variation in solids content at the thickener underflow was run, in Figure 6 it could be seen that for a stochastic generation of a certain thickening rate (average $60 \% \mathrm{w} / \mathrm{w}$ ), a variance of around $50 \%$ of the reported excess water could be expected; this example was run under arid conditions.
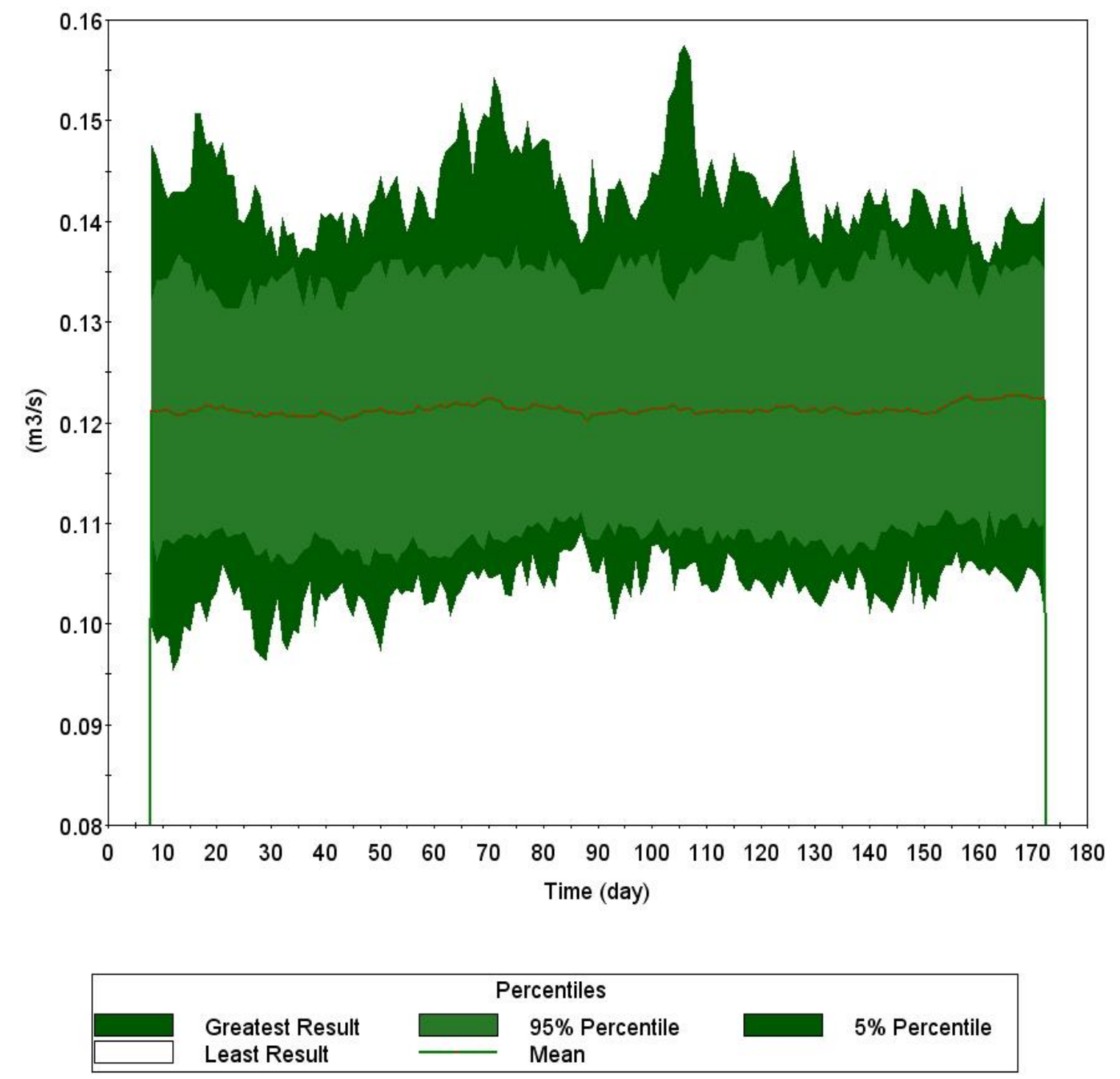

Figure 6 Daily variation of excess water - average $\mathrm{Cw}=60 \% \mathrm{w} / \mathrm{w}$

While the excess water estimated for average conditions could be used to design ponding capacity and/or pumping requirements, the excess water under critical conditions (considering variation of the thickening variability, for example) should be used to design freeboard requirements and evaluate appropriate contingency measures, especially during commissioning.

A good understanding of the expected amount of excess water would help in deciding the type of return water structures, strategies for managing the excess water and overall having a more reliable thickened tailings operation. 
Water balance of thickened tailings is important in order to understand the amount of free water that can be expected throughout the life of the operation. Some of the most influential parameters when calculating excess water from tailings, such as interstitial water, evaporation factor, infiltration and slurry solids content are usually treated as constant inputs. This could lead to an inefficient water management plan.

Modelling moisture changes in the tailings using saturated/unsaturated conditions can provide a reasonable estimation of the water lost to infiltration, evaporation and trapped in tailings pores, which can be used directly in the water balance model.

A probabilistic approach could be used to simulate variations in thickening rate, with standard deviation modelled accordingly with the expected performance of the thickener, this provides the best estimate of what the requirements for freeboard or contingencies needed during commissioning or where potential upsets of the thickener are expected.

\section{References}

Abu-Hejleh, A. and Znidarcic, D. (1995) Desiccation theory for soft cohesive soils, Journal of Geotechnical Engineering, Vol. 121:6, pp. 106-115.

Fredlund, D., Xing, A. and Huang, S. (1994) Predicting the permeability function for unsaturated soils using the soil-water characteristic curve, Canadian Geotechnical Journal, Vol. 31(3), pp. 521-533.

Oliveira-Filho, W. and van Zyl, D. (2006a) Modelling Discharge of Interstitial Water from Tailings Following Deposition, Part 1: Phenomenology and Model Descripition, Solos e Rochas, Sao Paulo, May-August 2006, Vol. 29(2), pp. 199-209.

Oliveira-Filho, W. and van Zyl, D. (2006b) Modelling Discharge of Interstitial Water from Tailings Following Deposition, Part 2: Application, Solos e Rochas, Sao Paulo, May-August 2006, Vol. 29(2), pp. 211-221.

Rykaart, M., Fredlund, M. and Stianson, J. (2001) Solving Tailings Impondment Water Balance Problems with 3-D Seepage Software, GEOSPEC, Geotechnical News, December 2001. 
